\title{
Hyperspectral diagnosis of nitrogen status in arbuscular mycorrhizal inoculated soybean leaves under three drought conditions
}

\author{
Yinli $\mathrm{Bi}^{1}$, Weiping Kong ${ }^{2,3^{*}}$, Wenjiang Huang ${ }^{3}$ \\ (1. State Key Laboratory of Coal Resources and Safe Mining, China University of Mining and Technology (Beijing), Beijing 100083, China; \\ 2. Key Laboratory of Quantitative Remote Sensing Information Technology, Academy of Opto-Electronics, Chinese Academy of Sciences, \\ Beijing 100094, China; 3. Key Laboratory of Digital Earth Science, Institute of Remote Sensing and Digital Earth, Chinese Academy of \\ Sciences, Beijing 100094, China)
}

\begin{abstract}
Precision diagnosis of leaf nitrogen $(\mathrm{N})$ content in arbuscular mycorrhizal inoculated crops under drought stress, using hyperspectral remote sensing technology, would be significant to evaluate the mycorrhizal effect on crop growth condition in the arid and semi-arid region. In this study, soybean plants with inoculation and non-inoculation treatments were grown under severe drought, moderate drought and normal irrigation conditions. Leaf spectral reflectance and several biochemical parameters were measured at $30 \mathrm{~d}, 45 \mathrm{~d}$ and $64 \mathrm{~d}$ after inoculation. Correlation analyses were conducted between leaf $\mathrm{N}$ content and the original and first derivative spectral reflectance. A series of first-order differential area indices and differential area ratio indices were proposed and explored. Results indicated that arbuscular mycorrhizal fungi improved leaf $\mathrm{N}$ content under drought stresses, the spectral reflectance in visible to red edge regions of inoculated plants was lower than that of non-inoculated plants. The first-order differential area index at bands of 638-648 nm achieved the best estimation and prediction accuracies in leaf $\mathrm{N}$ content inversion, with the determination coefficient of calibration of 0.72 , root mean square error of prediction and relative error of prediction of 0.46 and $11.60 \%$, respectively. This study provides a new insight for the evaluation of mycorrhizal effect under drought stress and opens up a new field of application for hyperspectral remote sensing. Keywords: leaf nitrogen content, hyperspectral remote sensing, mycorrhizal effect, soybean, drought stress
\end{abstract} DOI: $10.25165 /$ j.ijabe.20181106.4019

Citation: Bi Y L, Kong W P, Huang W J. Hyperspectral diagnosis of nitrogen status in arbuscular mycorrhizal inoculated soybean leaves under three drought conditions. Int J Agric \& Biol Eng, 2018; 11(6): 126-131.

\section{Introduction}

Drought is a problem of global concern and one of the most influential natural disasters affecting agricultural production in China $^{[1]}$. Drought stress inhibits nutrient absorption of crops and ultimately affects the growth and yield ${ }^{[2,3]}$. Arbuscular mycorrhizal fungi are a group of important microbes closely associated with soil fertility and plant nutrients. They can expand the absorption range and area of plant roots ${ }^{[4]}$ and improve plant uptake of water and nutrients in soil (e.g. N), resulting in enhanced plant resistance to drought ${ }^{[5]}$. Studies have reported that arbuscular mycorrhizal fungi can promote the nodulation in leguminous plants and $\mathrm{N}$ fixation by $\mathrm{N}$-fixating bacteria $^{[6]}$, thus improving the supply of $\mathrm{N}$ essential for plant growth. To find a quick, simple, large scale and non-destructive method is becoming increasingly important for diagnosing $\mathrm{N}$ status of crops.

In recent years, the spectral data measured from the leaf or canopy scale were used to analyze $\mathrm{N}$ content of crops, making it possible to monitor the growth condition and nutrient supply in a

Received date: 2017-12-05 Accepted date: 2018-05-28

Biographies: Yinli Bi, PhD, Professor, research interest: ecological restoration and agricultural remote sensing, Email: ylbi88@126.com; Wenjiang Huang, $\mathrm{PhD}$, Professor, research interest: the application of quantitative remote sensing in agriculture, Email: huangwj@, radi.ac.cn.

*Corresponding author: Weiping Kong, $\mathrm{PhD}$, Assistant Researcher, research interest: the application of quantitative remote sensing in agriculture. Key Laboratory of Quantitative Remote Sensing Information Technology, Academy of Opto-Electronics, Chinese Academy of Sciences, Beijing 100094, China. Tel: +86-10-82178645, Fax: +86-10-82178800, Email: kongwp@radi.ac.cn. large area. Numerous studies have focused on the estimation of leaf $\mathrm{N}$ content using hyperspectral remote sensing data for many crops, such as wheat ${ }^{[7]}$, spring maize ${ }^{[8]}$, potato ${ }^{[9]}$, etc. The characteristics of hyperspectral curves under drought stress have been analyzed ${ }^{[10]}$, and the relationships between canopy spectral reflectance and leaf $\mathrm{N}$ content have been used to generate different spectral indices, based on the inversion models for more accurate estimation of leaf $\mathrm{N}$ content in crops ${ }^{[11-13]}$. Feng et al. ${ }^{[7]}$ found that there is a better correlation between the $\mathrm{N}$ content in leaf of winter wheat and the double-peak area of red-edge spectral parameters calculated by the first derivative treatment of the original spectra. Lehnert et al. ${ }^{[14]}$ used the previously proposed spectral indices in visible spectrum reflectance to establish the inversion model for leaf $\mathrm{N}$ content of winter wheat, based on the partial least squares regression method, which can be used for real-time diagnosis of winter wheat $\mathrm{N}$ content. There are also studies using airborne, and satellite-borne remote sensing to estimate leaf $\mathrm{N}$ content in large scales and monitor crop nutrition status rapidly and non-destructively ${ }^{[15-17]}$.

However, a limited number of studies have been carried out to combine hyperspectral remote sensing with mycorrhizal effect to qualitatively diagnose the $\mathrm{N}$ status and quantitatively invert leaf $\mathrm{N}$ content for arbuscular mycorrhizal inoculated leguminous plants under drought stress conditions. The objectives of this study were 1) to compare leaf $\mathrm{N}$ content and the response characteristics of inoculated and non-inoculated soybean under three drought stress levels; 2) to analyze the correlation between leaf $\mathrm{N}$ content and the first derivative spectral reflectance; 3) to develop new spectral indices for the inversion of leaf $\mathrm{N}$ content of inoculated and non-inoculated soybean. 


\section{Materials and methods}

\subsection{Experimental design}

The study was conducted in the microbial remediation greenhouse at the China University of Mining and Technology (Beijing), during the end of July 2013. Soybean (cv. Zhonhuang 35) seeds were provided by Chinese Academy of Agricultural Sciences and planted in the pots $(24 \mathrm{~cm}$ (top diameter) $\times 15 \mathrm{~cm}$ (bottom diameter) $\times 18 \mathrm{~cm}$ (height)). Arbuscular mycorrhizal Glomus intraradices (G.i.) was provided by Plant Nutrition and Resources Research Institute, Beijing Academy of Agriculture and Forestry Sciences and preserved in our laboratory. The samples of $4.8 \mathrm{~kg} /$ pot of sandy soil were autoclaved, dried and irrigated to the maximum water holding capacity (about 25.7\%). Nutrient solution containing $\mathrm{NH}_{4} \mathrm{NO}_{3}, \mathrm{KH}_{2} \mathrm{PO}_{4}$ and $\mathrm{KNO}_{3}$ was added as basal fertilizer before sowing seeds. The mass fractions of $\mathrm{N}$, phosphorus $(\mathrm{P})$, potassium $(\mathrm{K})$ in the soil were $100 \times 10^{-6}, 10 \times 10^{-6}$ and $150 \times 10^{-6}$, respectively. The plants were thinned to 2 healthy and uniformed plants per pot, and subjected to drought stress at the fourth week of emergence. Three drought levels were tested, i.e. severe drought (W1), moderate drought (W2) and normal irrigation (W3), with the maximum water holding capacity of $35 \%, 55 \%$ and $75 \%$, respectively. For each drought level, the plants were inoculated $(+\mathrm{M})$ and non-inoculated, serving as control (CK). Each treatment was repeated four times and harvested three times, with a total of 72 pots. For $+\mathrm{M}$ treatment, $100 \mathrm{~g}$ of $G . i$ was added to each pot, while CK was added with an equal amount of sandy soil to ensure equal matrix mass. All treatments were randomly arranged in the greenhouse and supplemented with an appropriate amount of water to compensate evaporated water by weighing the pots.

\subsection{Data acquisition and preprocessing}

Spectral reflectance and relevant biochemical parameters of leaves were measured at Day 30 (the tenth day after drought stress), Day 45 and Day 64 after the inoculation. 66 sets of data were obtained after removing the data with gross errors.

\subsubsection{Spectral measurement}

A FieldSpec3 spectrometer (Analytical Spectral Devices, USA) was used to measure the spectral reflectance of leaves. The instrument was fitted with a $25^{\circ}$ field of view fiber optics, recording reflectance between $350 \mathrm{~nm}$ and $1050 \mathrm{~nm}$ with a sampling interval of $1.40 \mathrm{~nm}$ and a resolution of $3 \mathrm{~nm}$, and reflectance between 1000-2500 $\mathrm{nm}$ with a sampling interval of $2 \mathrm{~nm}$ and a resolution of $10 \mathrm{~nm}$. Each spectral measurement was preceded by an optimization measurement, and a white reference measurement was taken every 15 min using a white Spectralon ${ }^{\circledR}$ (Labsphere, Inc. New Hampshire, USA) reference panel. For each pot, two leaves were selected at top, middle and low positions, and each leaf was measured from four angles mutually rotated for $90^{\circ}$ to reduce the measurement error caused by leaf curl. Ten scans were performed at each angle, yielding a set of 40 scans, which were averaged and used as the spectral reflectance data for the leaf. For each pot, six averaged leaf spectra were generated to represent the reflectance spectra of the soybean plants.

\subsubsection{Spectral data preprocessing}

The method of nine-point weighted moving average ${ }^{[18]}$ was used to preprocess the spectral data. It can effectively eliminate the random errors and is capable of retaining the original spectral characteristics. The spectral reflectance was calculated as follows:

$$
\begin{aligned}
R_{i}^{\prime}= & 0.04 R_{i-4}+0.08 R_{i-3}+0.12 R_{i-2}+0.16 R_{i-1}+0.2 R_{i}+ \\
& 0.16 R_{i+1}+0.12 R_{i+2}+0.08 R_{i+3}+0.04 R_{i+4}
\end{aligned}
$$

where, $R_{i}^{\prime}$ is the reflectance value after weighting by the reflectance of nine-point; $R_{i}$ is the original reflectance at wavelength of $i \mathrm{~nm}$; $R_{i-4}, R_{i-3}, R_{i-2}, R_{i-1}, R_{i+1}, R_{i+2}, R_{i+3}, R_{i+4}$ are the original reflectance at 4 wavelengths that before and after the wavelength $i \mathrm{~nm}$, respectively.

\subsubsection{Measurement of leaf biochemical parameters}

After the spectral measurement, the leaves were used for biochemical parameter determination. Leaf $\mathrm{N}$ content was determined by the Kjeldahl method. The leaves were grinded, sieved and weighed $0.2 \mathrm{~g}$ (be accurate to $0.0001 \mathrm{~g}$ ), after drying the samples in an oven at $80^{\circ} \mathrm{C}$ for $48 \mathrm{~h}$. Then they were digested with $\mathrm{H}_{2} \mathrm{SO}_{4}-\mathrm{H}_{2} \mathrm{O}_{2}$ before being used for $\mathrm{N}$ determination. Leaf chlorophyll content was measured using a handheld chlorophyll meter (SPAD-502, Minola Osaka Company, Ltd., Japan). 10-20 spots on a leaf were randomly selected and measured. Their average value was used to represent the leaf chlorophyll content of this leaf. Mycorrhizal infection rate was determined using the Phillips and Hayman method ${ }^{[19]}$ and hyphal density was determined by the grid intersection method ${ }^{[5]}$.

\subsection{Construction of differential area indices and statistical analysis}

A series of first-order differential area indices (DAI) and differential area ratio indices (DARI) were established in this study. They are areas surrounded by the curve of the first derivative spectra and $x$ axis in the $\mathrm{N}$-related sensitive spectral regions, which were implemented using Matlab 8.3 (The MathWorks, Inc., Nat-ick, MA, USA). They are formulated as:

$$
\begin{gathered}
\mathrm{DAI}_{\lambda 1-\lambda 2}=\int_{\lambda 1}^{\lambda 2} \frac{d R(\lambda)}{\lambda} d(\lambda) \\
\mathrm{DARI}=\mathrm{DAI}_{\lambda 1-\lambda 2} / \mathrm{DAI}_{\lambda 3-\lambda 4}
\end{gathered}
$$

where, $\mathrm{DAI}_{\lambda 1-\lambda 2}$ indicates the first-order differential area from $\lambda 1$ to $\lambda 2 \mathrm{~nm}$, wavelength $\lambda 1-\lambda 2 \mathrm{~nm}$ are the N-related sensitive spectral regions, DARI is the ratio of two different $\mathrm{DAI}_{\lambda 1-\lambda 2}$ indices.

Linear, logarithmic, second-order polynomial, power and exponential regressions were used to model the relationship between leaf $\mathrm{N}$ content and spectral indices. The stability and reliability of the models were assessed by comparing the determination coefficient of calibration $\left(R_{c}{ }^{2}\right)$, the $F$ value, and root mean square error of calibration $\left(\mathrm{RMSE}_{\mathrm{c}}\right)$. The prediction ability of models was evaluated by the determination coefficient of prediction $\left(R_{p}{ }^{2}\right)$, root mean square error of prediction $\left(\mathrm{RMSE}_{\mathrm{p}}\right)$ and relative error of prediction $\left(\mathrm{RE}_{\mathrm{p}}\right)$. From 66 samples, 46 samples were randomly selected for building the inversion models, and the remaining 20 independent samples were used for the validation.

\section{Results and discussion}

\subsection{Changes of leaf $\mathbf{N}$ content in soybean after inoculation under drought stresses}

Infection rate is a measurement of association between the arbuscular mycorrhizal fungi and plants ${ }^{[20]}$, and hyphal density can indicate the ability of the mycorrhiza in promoting plant growth and nutrient absorption. Longer mycelium is better for the plant roots to absorb and transport water and nutrients ${ }^{[5]}$. As shown in Table 1, under different drought stress levels, the infection rates of roots were different, and the hyphal density increased with the decreasing of drought stress levels. At $64 \mathrm{~d}$ after inoculation, the hyphal density was up to $1.99 \mathrm{~m} / \mathrm{g}$ for normally irrigated soybean. 
Table 1 Mycorrhizal infection rate and hyphal density of soybean plant roots under different drought stress levels

\begin{tabular}{|c|c|c|c|c|c|c|c|}
\hline \multirow{2}{*}{\multicolumn{2}{|c|}{ Drought stress level }} & \multicolumn{2}{|c|}{$30 \mathrm{~d}$ after inoculation } & \multicolumn{2}{|c|}{$45 \mathrm{~d}$ after inoculation } & \multicolumn{2}{|c|}{$64 \mathrm{~d}$ after inoculation } \\
\hline & & Infection rate $/ \%$ & Hyphal density $/ \mathrm{m} \cdot \mathrm{g}^{-1}$ & Infection rate $/ \%$ & Hyphal density $/ \mathrm{m} \cdot \mathrm{g}^{-1}$ & Infection rate $/ \%$ & Hyphal density $/ \mathrm{m} \cdot \mathrm{g}^{-1}$ \\
\hline \multirow{2}{*}{ W1 } & $+\mathrm{M}$ & $46.67 \pm 3.97$ & $0.44 \pm 0.04$ & $66.67 \pm 12.1$ & $0.66 \pm 0.04$ & $88.30 \pm 1.67$ & $1.16 \pm 0.05$ \\
\hline & CK & 0 & 0 & 0 & 0 & 0 & 0 \\
\hline \multirow{2}{*}{ W2 } & $+\mathrm{M}$ & $60.83 \pm 9.56$ & $0.96 \pm 0.03$ & $91.67 \pm 3.47$ & $1.19 \pm 0.03$ & $96.00 \pm 4.98$ & $1.48 \pm 0.06$ \\
\hline & CK & 0 & 0 & 0 & 0 & 0 & 0 \\
\hline \multirow{2}{*}{ W3 } & $+\mathrm{M}$ & $75.00 \pm 5.18$ & $1.09 \pm 0.07$ & $100.00 \pm 0$ & $1.31 \pm 0.05$ & $100.00 \pm 0$ & $1.99 \pm 0.03$ \\
\hline & CK & 0 & 0 & 0 & 0 & 0 & 0 \\
\hline
\end{tabular}

The dynamic changes of leaf $\mathrm{N}$ content of inoculated $(+\mathrm{M})$ and non-inoculated (CK) mycorrhizal treatments after $30 \mathrm{~d}, 45 \mathrm{~d}$ and $64 \mathrm{~d}$ under different drought stresses are presented in Figure 1. At $45 \mathrm{~d}$ and $64 \mathrm{~d}$ after inoculation, leaf $\mathrm{N}$ content in $+\mathrm{M}$ and $\mathrm{CK}$ soybean plants decreased with the increasing of drought stress levels. At $64 \mathrm{~d}$, between two drought stresses of severe drought (W1) and normal irrigation (W3), there were significant differences in leaf $\mathrm{N}$ content in $+\mathrm{M}$ plants, and in $\mathrm{CK}$ plants as well. Furthermore, under the same drought stress level, leaf $\mathrm{N}$ content at these two dates was significantly higher in $+\mathrm{M}$ plants than that in CK plants. However, $30 \mathrm{~d}$ after the inoculation, the difference in $\mathrm{N}$ content between $+\mathrm{M}$ and $\mathrm{CK}$ treatments was not significant under moderate drought stress level (W2) at $30 \mathrm{~d}$. This is probably because the plants had been subjected to drought stress only for $9 \mathrm{~d}$, with a low mycorrhizal infection rate and a low hyphal density. Nevertheless, at the other two dates after inoculation, the plants had gained benefits through the symbiotic association formed with the fungi, resulting in the improved capability in the $\mathrm{N}$ uptake, and consequently, leading to a higher $\mathrm{N}$ content. Therefore, leaf $\mathrm{N}$ content can be used as an indicator to evaluate the effect of mycorrhiza under drought stress conditions.

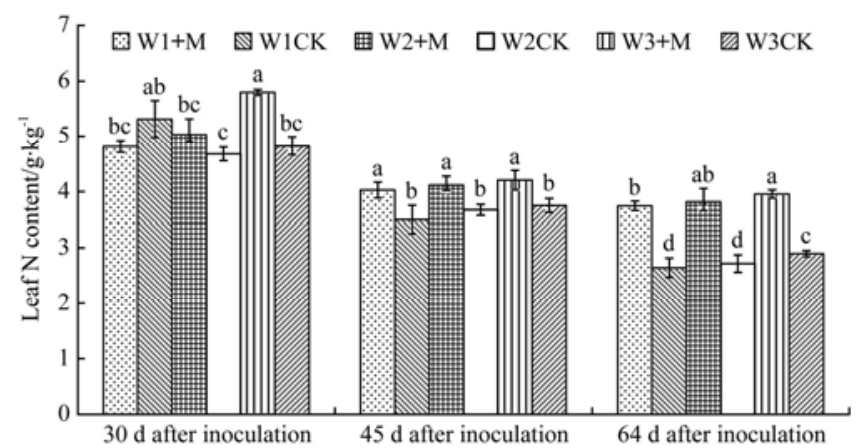

Figure 1 Changes of leaf $\mathrm{N}$ content after $30 \mathrm{~d}, 45 \mathrm{~d}$ and $64 \mathrm{~d}$ of inoculation under different drought stresses

Differences in the $\mathrm{N}$ content at the same inoculation date between the treatments were tested by the least significant difference (LSD) method. Bars labelled with different letters indicate significant difference $(p<0.05)$; W1, W2 and W3 indicate severe drought, moderate drought and normal irrigation, respectively; $+\mathrm{M}$ and $\mathrm{CK}$ indicate inoculation and non-inoculation treatments, respectively. W1CK indicates treatment with severe drought and non-inoculation, $\mathrm{W} 1+\mathrm{M}$ indicates treatment with severe drought and inoculation, etc.

\subsection{Correlation between leaf $\mathrm{N}$ content and SPAD values}

$\mathrm{N}$ is a constituent of chlorophyll, while SPAD value is a direct indicator of chlorophyll ${ }^{[21]}$. Figure 2 shows the correlation between leaf $\mathrm{N}$ content and SPAD values under different drought stress levels. Leaf $\mathrm{N}$ content was significantly correlated to the
SPAD values in $+\mathrm{M}$ and $\mathrm{CK}$ soybean plants, with a correlation coefficient of $0.80(p<0.01)$. As shown in Figure 2, leaf $\mathrm{N}$ content increased with the increasing of SPAD values, which is consistent with the findings of many studies ${ }^{[22-24]}$. This result may present convincing evidence that extraction and analysis of the spectral information on chlorophyll absorption bands can be used to diagnose $\mathrm{N}$ status in soybean leaves with inoculated and non-inoculated under different drought stresses. Most importantly, this would provide a new method for the evaluation of mycorrhizal effect.

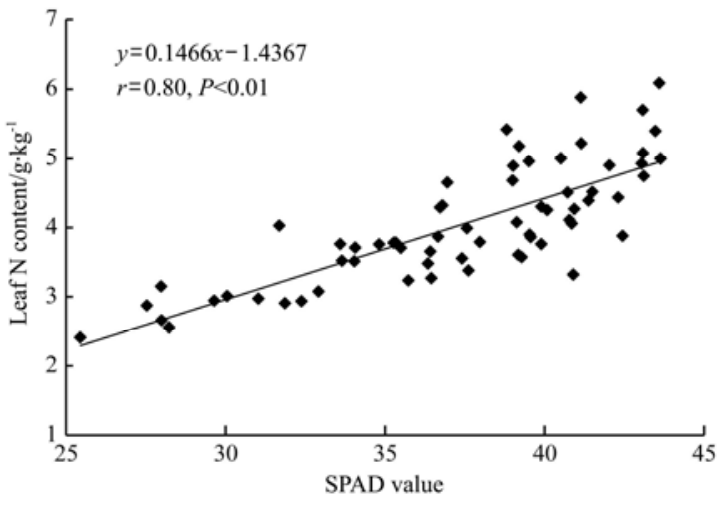

Figure 2 Correlation between leaf $\mathrm{N}$ content and SPAD values

3.3 Response characteristics of spectral reflectance of inoculated and non-inoculated soybean under drought stresses

Leaf spectral reflectance is the result of several intricately coupled parameters, i.e. pigment content, nutritional content and morphological characteristics, etc. ${ }^{[9]}$ In the visible to red edge bands $(400-740 \mathrm{~nm})$, it is dominated by the absorption of leaf chlorophyll content. Considering the correlation between leaf $\mathrm{N}$ and SPAD values (section 3.2), the spectral features in visible to red-edge bands would be used to indirectly reflect leaf $\mathrm{N}$ content. The spectral reflectance measured at $45 \mathrm{~d}$ after inoculation was used as an example to illustrate the response characteristics of the soybean reflectance spectrum under different experimental treatments. As shown in Figure 3, the reflectance of both $+\mathrm{M}$ and CK plants in the visible to red edge regions increased with the increasing of drought stress levels. This is mainly due to the damaged chloroplast and reduced synthesis of chlorophyll caused by the water deficit, and then resulting in the reduction of chlorophyll content. In the meanwhile, the leaves became yellow, which led to less light absorption and higher reflectance. However, under the three drought stress conditions, the reflectance of $+\mathrm{M}$ plants was all lower than that of the corresponding CK plants, indicating that the former had more chlorophyll content than the latter. Thus we could primarily and qualitatively infer the $\mathrm{N}$ status in the inoculated and non-inoculated soybean under the three drought stresses. 


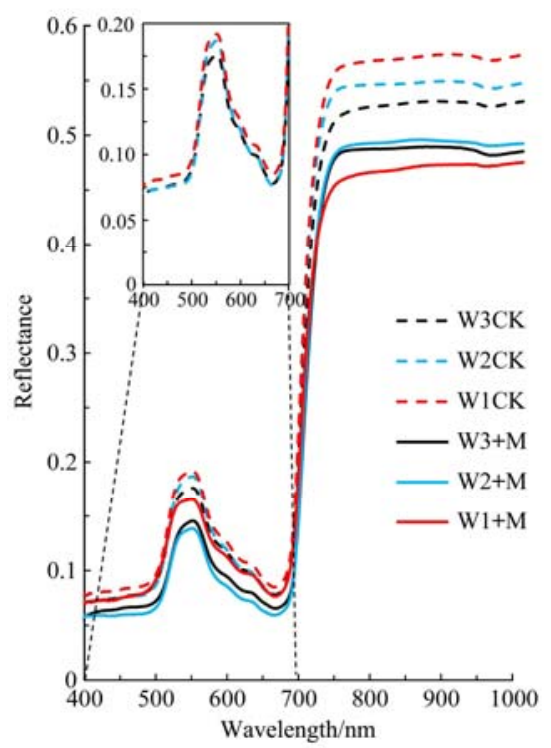

Note: $\mathrm{W} 1, \mathrm{~W} 2$ and $\mathrm{W} 3$ represent severe, moderate drought and normal irrigation, respectively; $+\mathrm{M}$ and $\mathrm{CK}$ represent inoculation and non-inoculation, respectively. $\mathrm{W} 1 \mathrm{CK}$ indicates the treatment with severe drought and non-inoculation, $\mathrm{W} 1+\mathrm{M}$ indicates the treatment with severe drought and inoculation, etc.

Figure 3 Spectral reflectance of soybean under different drought stress conditions

\subsection{Correlation between leaf $N$ content and the first derivative spectral reflectance}

The correlations between leaf $\mathrm{N}$ content and reflectance of the original spectra and the first derivative spectra were analyzed, the results are showed in Figure 4. Compared to the original spectral reflectance, the correlation coefficient relation to leaf $\mathrm{N}$ content was higher after the first derivative processing, which indicates that the derivate spectra improved the quantitative accuracy. The result is also confirmed by other relative literatures ${ }^{[7,8]}$. This is because first derivative transformation can enhance the subtle changes in the slope of spectral curves and minimize the spectral noise ${ }^{[25]}$.

From Figure 4, in the wavebands of 543-547 nm, 597-613 nm, $638-648 \mathrm{~nm}$ and $678-696 \mathrm{~nm}$, the correlation coefficients between the first derivative spectral reflectance and leaf total $\mathrm{N}$ content reached higher than 0.75 . Therefore, these bands were regarded as the sensitive spectral regions for diagnosis of $\mathrm{N}$ content under drought stress conditions. The established spectral indices and the correlations with leaf $\mathrm{N}$ are summarized in Table 2. Significant correlations $(p<0.01)$ were observed for several spectral indices, i.e. $\mathrm{DAI}_{543-547}, \mathrm{AI}_{597-613}, \mathrm{DAI}_{638-648}, \mathrm{DAI}_{678-696}, \mathrm{DAI}_{597-613} / \mathrm{DAI}_{638-648}$ and $\mathrm{DAI}_{638-648} / \mathrm{DAI}_{678-696}$. Therefore, these indices can be used to invert the leaf $\mathrm{N}$ content in soybean.

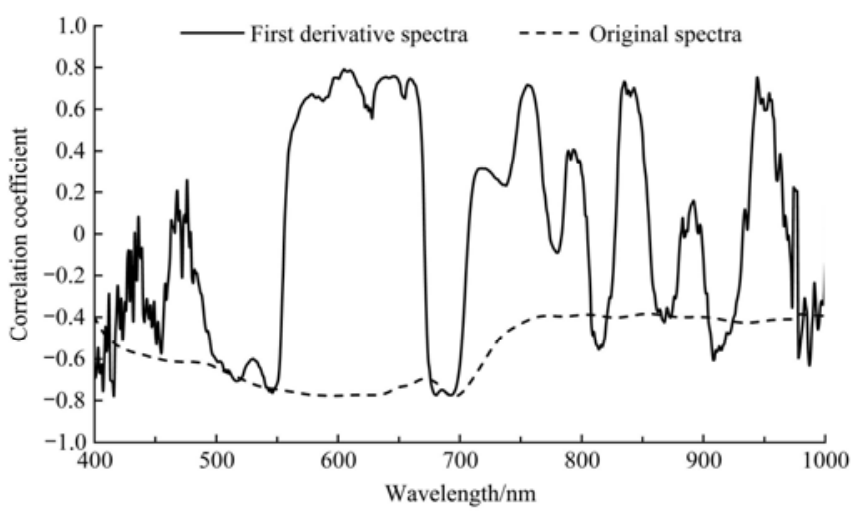

Figure 4 Correlations between leaf $\mathrm{N}$ content and reflectance of the original spectra and the first derivative spectra

Table 2 Correlations between leaf $\mathbf{N}$ content and spectral indices

\begin{tabular}{|c|c|c|}
\hline Spectral index & Description & Correlation coefficient \\
\hline $\mathrm{DAI}_{543-547}$ & The first-order differential area from 543 to $547 \mathrm{~nm}$ & $-0.75^{* *}$ \\
\hline $\mathrm{DAI}_{597-613}$ & The first-order differential area from 597 to $613 \mathrm{~nm}$ & $-0.76^{* *}$ \\
\hline $\mathrm{DAI}_{638-648}$ & The first-order differential area from 638 to $648 \mathrm{~nm}$ & $-0.80^{* *}$ \\
\hline DAI $_{678-696}$ & The first-order differential area from 678 to $696 \mathrm{~nm}$ & $-0.77^{* *}$ \\
\hline $\mathrm{DAI}_{543-547} / \mathrm{DAI}_{597-613}$ & Ratio of the first-order differential area from 543 to $547 \mathrm{~nm}$ and the area from 597 to $613 \mathrm{~nm}$ & -0.38 \\
\hline $\mathrm{DAI}_{543-547} / \mathrm{DAI}_{678-696}$ & Ratio of the first-order differential area from 543 to $547 \mathrm{~nm}$ to the area from 678 to $696 \mathrm{~nm}$ & -0.17 \\
\hline $\mathrm{DAI}_{597-613} / \mathrm{DAI}_{638-648}$ & Ratio of first-order differential area from 597 to $613 \mathrm{~nm}$ to the area from 638 to $648 \mathrm{~nm}$ & $0.71^{* *}$ \\
\hline $\mathrm{DAI}_{597-613} / \mathrm{DAI}_{678-696}$ & Ratio of first-order differential area from 597 to $613 \mathrm{~nm}$ to the area from 678 to $696 \mathrm{~nm}$ & 0.48 \\
\hline $\mathrm{DAI}_{638-648} / \mathrm{DAI}_{678-696}$ & Ratio of first-order differential area from 638 to $648 \mathrm{~nm}$ to the area from 678 to $696 \mathrm{~nm}$ & $-0.57^{* *}$ \\
\hline
\end{tabular}

Note: $* *$ denotes significance at 0.01 level.

\subsection{Inversion models for leaf $\mathbf{N}$ content and model validation}

It should be noted that five spectral indices including $\mathrm{DAI}_{543-547}$, $\mathrm{DAI}_{597-613}, \quad \mathrm{DAI}_{638-648}, \quad \mathrm{DAI}_{678-696}, \quad \mathrm{DAI}_{597-613} / \mathrm{DAI}_{638-648}$, with correlation coefficients of greater than 0.7 , were selected from Table 2 , and then analyzed to establish the inversion models for leaf $\mathrm{N}$ content using linear, logarithmic, quadratic, power function and exponential regression methods, respectively. The results are shown in Table 3.

According to Table 3, for the $\mathrm{DAI}_{638-648}$, the optimal inversion model was a power function with the maximum $R_{c}{ }^{2}$ and $F$ value $\left(R_{c}{ }^{2}=0.72, F=110.97\right)$, and the minimum $\operatorname{RMSE}_{\mathrm{c}}\left(\operatorname{RMSE}_{\mathrm{c}}=0.48\right)$. For the other indices, the optimal inversion models were all exponential models. The scatterplots of the optimal models based on the five spectral indices are shown in Figure 5. The DAI ${ }_{638-648}$ model based on power function has the greatest $R_{c}{ }^{2}$ and $F$ value and smallest $\mathrm{RMSE}_{\mathrm{c}}$, indicating that it is the most stable model with the highest accuracy, followed by the $\mathrm{DAI}_{597-613}$ model based on the exponential function.

The results of model validation are presented in Table 3 as well. For each spectral index, only the corresponding best inversion model was validated. $R_{p}{ }^{2}$ values for the five inversion models are more than 0.5 with $\mathrm{RMSE}_{\mathrm{p}}$ and $\mathrm{RE}_{\mathrm{p}}$ of less than 0.6 and $14 \%$, respectively. However, the model based on $\mathrm{DAI}_{638-648}$ index has the largest $R_{p}{ }^{2}$ value of 0.71 , and smallest $\mathrm{RMSE}_{\mathrm{p}}$ and $\mathrm{RE}_{\mathrm{p}}$ of 0.46 and $11.60 \%$, respectively, indicating that it has the best prediction ability among all models tested. Obviously, it is the best model for the assessment of leaf $\mathrm{N}$ content, and can be used to diagnose $\mathrm{N}$ status for the inoculated and non-inoculated soybean under drought stress conditions. 
Table 3 Leaf $\mathrm{N}$ content inversion and validation, and error analysis

\begin{tabular}{|c|c|c|c|c|c|c|c|}
\hline \multirow{2}{*}{ Spectral index } & \multirow{2}{*}{ Model } & \multicolumn{3}{|c|}{ Modelling parameter $(n=46)$} & \multicolumn{3}{|c|}{ Validation parameter $(n=20)$} \\
\hline & & $R_{c}{ }^{2}$ & $F$ & $\mathrm{RMSE}_{\mathrm{c}}$ & $R_{p}{ }^{2}$ & $\mathrm{RMSE}_{\mathrm{p}}$ & $\mathrm{RE}_{\mathrm{p}} / \%$ \\
\hline \multirow{5}{*}{$\mathrm{DAI}_{543-547}$} & $y=5.39-882.28 x$ & 0.58 & 58.34 & 0.54 & & & \\
\hline & $y=3.26-1.10 \ln x$ & 0.54 & 50.61 & 0.56 & & & \\
\hline & $y=5.29-730.29 x-46905.15 x^{2}$ & 0.57 & 28.60 & 0.55 & & & \\
\hline & $y=0.64 x^{-0.28}$ & 0.53 & 49.39 & 0.58 & & & \\
\hline & $y=5.60 \mathrm{e}^{-226.46 x}$ & 0.61 & 65.82 & 0.54 & 0.58 & 0.55 & 12.68 \\
\hline \multirow{5}{*}{$\mathrm{DAI}_{597-613}$} & $y=6.51-217.86 x$ & 0.63 & 70.05 & 0.50 & & & \\
\hline & $y=-7.26-2.51 \ln x$ & 0.61 & 68.68 & 0.51 & & & \\
\hline & $y=6.63-238.44 x+829.01 x^{2}$ & 0.63 & 36.18 & 0.50 & & & \\
\hline & $y=0.21 x^{-0.65}$ & 0.68 & 86.93 & 0.53 & & & \\
\hline & $y=7.60 \mathrm{e}^{-57.53 x}$ & 0.70 & 101.99 & 0.49 & 0.62 & 0.53 & 13.54 \\
\hline \multirow{5}{*}{$\mathrm{DAI}_{638-648}$} & $y=5.21-130.25 x$ & 0.58 & 60.40 & 0.53 & & & \\
\hline & $y=-3.11-1.48 \ln x$ & 0.65 & 78.76 & 0.49 & & & \\
\hline & $y=6.24-340.91 x+8132.95 x^{2}$ & 0.64 & 38.53 & 0.49 & & & \\
\hline & $y=0.60 x^{-0.39}$ & 0.72 & 110.97 & 0.48 & 0.71 & 0.46 & 11.60 \\
\hline & $y=5.43 \mathrm{e}^{-35.20 x}$ & 0.68 & 91.56 & 0.51 & & & \\
\hline \multirow{5}{*}{$\mathrm{DAI}_{678-696}$} & $y=5.78-29.61 x$ & 0.59 & 62.55 & 0.52 & & & \\
\hline & $y=-1.09-1.77 \ln x$ & 0.57 & 57.27 & 0.54 & & & \\
\hline & $y=5.93-34.78 x+38.47 x^{2}$ & 0.59 & 30.61 & 0.53 & & & \\
\hline & $y=1.04 x^{-0.46}$ & 0.61 & 70.58 & 0.56 & & & \\
\hline & $y=6.29 \mathrm{e}^{-7.88 x}$ & 0.66 & 83.33 & 0.53 & 0.61 & 0.53 & 13.10 \\
\hline \multirow{5}{*}{$\mathrm{DAI}_{597-613} / \mathrm{DAI}_{638-648}$} & $y=0.99+2.18 x$ & 0.51 & 44.65 & 0.59 & & & \\
\hline & $y=3.22+2.61 \ln x$ & 0.49 & 42.76 & 0.60 & & & \\
\hline & $y=1.86+0.70 x+0.59 x^{2}$ & 0.51 & 22.01 & 0.57 & & & \\
\hline & $y=3.17 x^{0.70}$ & 0.55 & 57.61 & 0.58 & & & \\
\hline & $y=1.75 \mathrm{e}^{0.58 x}$ & 0.57 & 58.21 & 0.58 & 0.64 & 0.51 & 12.10 \\
\hline
\end{tabular}

Note: $x$ indicates the spectral index and $y$ indicates leaf $\mathrm{N}$ content. $\quad$ The best inversion model for each spectral index is in bold.
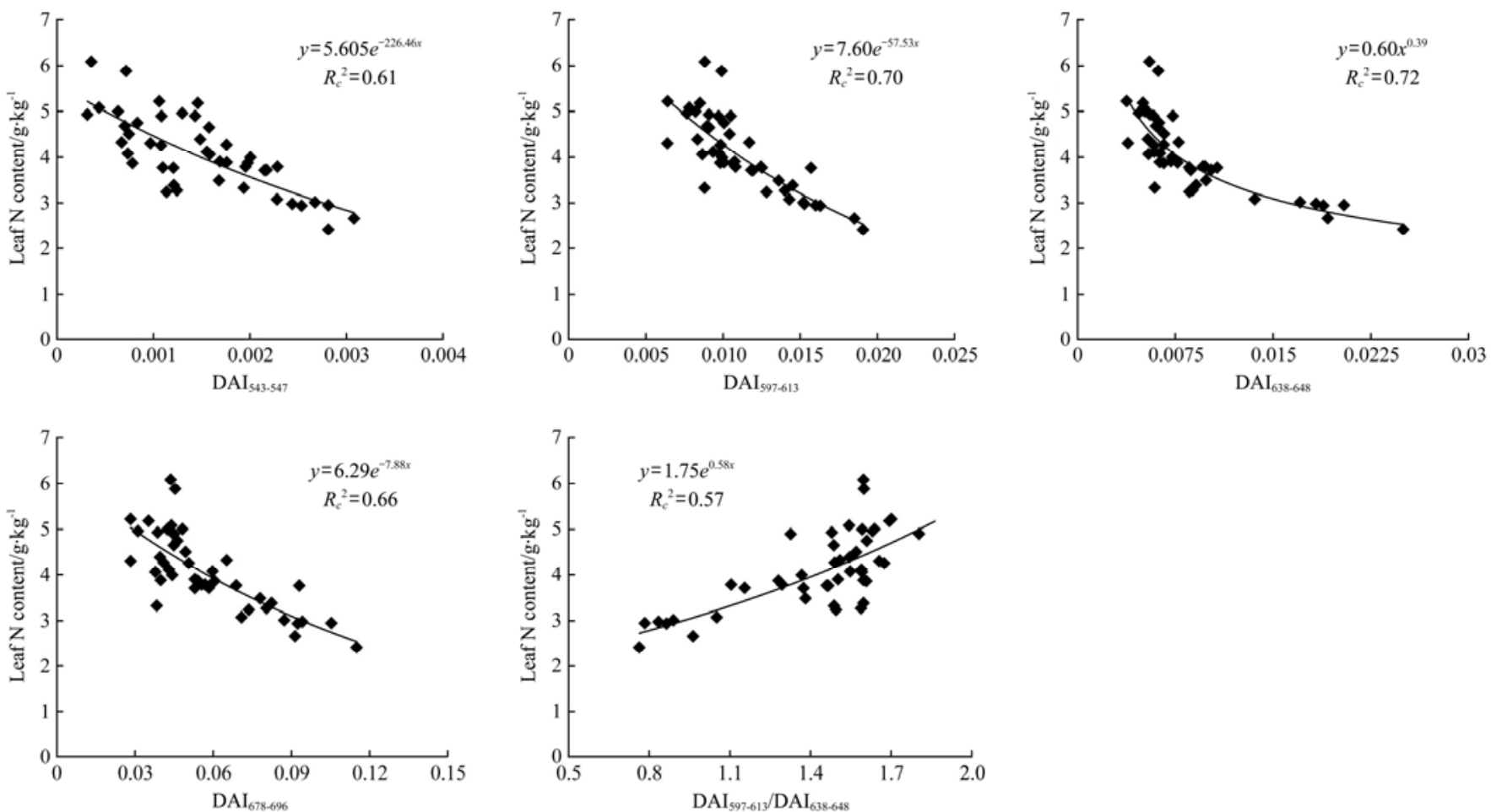

Figure 5 Scatterplots of the optimal inversion models based on the spectral indices $(n=46)$

\section{Conclusions}

This study showed that it is feasible to estimate leaf $\mathrm{N}$ content of inoculated soybean using hyperspectral remote sensing technology. Leaf $\mathrm{N}$ content in both inoculated and non-inoculated soybean decreased as drought stresses increased at $45 \mathrm{~d}$ and $64 \mathrm{~d}$ after inoculation. Under the same drought stress condition, the $\mathrm{N}$ content in inoculated plants was significantly higher than that in 
non-inoculated plants, indicating that mycorrhizal inoculation increases the leaf $\mathrm{N}$ content. The spectral features in visible to red edge bands sensitive to the chlorophyll content can be used to indirectly and qualitatively diagnose $\mathrm{N}$ status in inoculated and non-inoculated soybean under drought stress, due to a significant (positive) correlation between $\mathrm{N}$ content and SPAD values. The visible bands of 543-547 nm, 597-613 nm, 638-648 nm and 678$696 \mathrm{~nm}$ are sensitive to leaf $\mathrm{N}$ content. We found that the first-order differential area index with bands from 638-648 nm $\left(\mathrm{DAI}_{638-648}\right)$ is the best spectral index for leaf $\mathrm{N}$ inversion. The inversion models developed in this study were based on the dataset obtained from the pot experiment in the greenhouse. However, it is more meaningful to diagnose the $\mathrm{N}$ status of inoculated crops in the field and evaluate the effect of mycorrhiza using remote sensing technology. Future validation is needed to test the applicability of the models on the field or regional scale, and to assess the performance of the differential area indices in leaf $\mathrm{N}$ estimation for other crops.

\section{Acknowledgments}

The work was supported by the National Natural Science Foundation of China (51574253) and the National Key Research and Development Program of China (2016YFC0501106). The authors are grateful to Ms. Shunlin Chen, Mr. Yanbo Feng and Mr. Haiyang $\mathrm{Yu}$ for their assistance in data collection. Our appreciation also goes to the anonymous reviewers for valuable suggestions and comments.

\section{[References]}

[1] Zhang J, Wu J, Zhou L, Lei T, Liu M. Comparative study on remotely sensed methods of monitoring agricultural drought based on MODIS data. Remote Sensing Information, 2012; 27(5): 48-54.

[2] Steward P R, Dougill A J, Thierfelder C, Pittelkow C M, Stringer L C, Kudzala M, et al. The adaptive capacity of maize-based conservation agriculture systems to climate stress in tropical and subtropical environments: A meta-regression of yields. Agriculture Ecosystems \& Environment, 2018; 251: 194-202.

[3] Bertolli S C, Rapchan G L, Souza G M. Photosynthetic limitations caused by different rates of water-deficit induction in Glycine max and Vigna unguiculata. Photosynthetica, 2012; 50(3): 329-36.

[4] Gupta M L, Prasad A, Ram M, Kumar S. Effect of the vesicular-arbuscular mycorrhizal (VAM) fungus Glomus fasciculatum on the essential oil yield related characters and nutrient acquisition in the crops of different cultivars of menthol mint (Mentha arvensis) under field conditions. Bioresource Technology, 2002; 81(1): 77-9.

[5] Bi Y L, Li X L, Wang H G, Christie P. Establishment of monoxenic culture between the arbuscular mycorrhizal fungus Glomus sinuosum and Ri T-DNA-transformed carrot roots. Plant and Soil, 2004; 261(1-2): 239-244.

[6] Antunes P M, de Varennes A, Rajcan I, Goss M J. Accumulation of specific flavonoids in soybean (Glycine max L. Merr.) as a function of the early tripartite symbiosis with arbuscular mycorrhizal fungi and Bradyrhizobium japonicum (Kirchner) Jordan. Soil Biology \& Biochemistry, 2006; 38(6): 1234-1242.

[7] Feng W, Guo B B, Wang Z J, He L, Song X, Wang Y H, et al. Measuring leaf nitrogen concentration in-winter wheat using double-peak spectral reflection remote sensing data. Field Crops Research, 2014; 159: 43-52.
[8] Chen P F, Haboudane D, Tremblay N, Wang J H, Vigneault P, Li B G. New spectral indicator assessing the efficiency of crop nitrogen treatment in corn and wheat. Remote Sensing of Environment, 2010; 114(9): 1987-1997.

[9] Clevers J, Kooistra L. Using hyperspectral remote sensing data for retrieving canopy chlorophyll and nitrogen content. IEEE Journal of Selected Topics in Applied Earth Observations and Remote Sensing, 2012; 5(2): 574-583.

[10] Wang H B, Feng R, Ji R P, Wu J W, Yu W Y, Zhang Y S. Hyperspectral characteristics of spring maize from jointing to silking stage under drought stress. Spectroscopy and Spectral Analysis, 2012; 32(12): 3358-3332.

[11] Tian Y C, Gu K J, Chu X, Yao X, Cao W X, Zhu Y. Comparison of different hyperspectral vegetation indices for canopy leaf nitrogen concentration estimation in rice. Plant and Soil, 2014; 376(1-2): 193-209.

[12] Ranjan R, Chopra U K, Sahoo R N, Singh A K, Pradhan S. Assessment of plant nitrogen stress in wheat (Triticum aestivum L.) through hyperspectral indices. International Journal Of Remote Sensing, 2012; 33(20): 6342-6360.

[13] Herrmann I, Karnieli A, Bonfil D J, Cohen Y, Alchanatis V. SWIR-based spectral indices for assessing nitrogen content in potato fields. International Journal of Remote Sensing, 2010; 31(19): 5127-5143.

[14] Lehnert L W, Meyer H, Meyer N, Reudenbach C, Bendix J. A hyperspectral indicator system for rangeland degradation on the Tibetan Plateau: A case study towards spaceborne monitoring. Ecol Indic, 2014; 39: 54-64.

[15] Ryu C, Suguri M, Umeda M. Model for predicting the nitrogen content of rice at panicle initiation stage using data from airborne hyperspectral remote sensing. Biosystems Engineering, 2009; 104(4): 465-475.

[16] Li F, Mistele B, Hu Y C, Chen X P, Schmidhalter U. Reflectance estimation of canopy nitrogen content in winter wheat using optimised hyperspectral spectral indices and partial least squares regression. European Journal of Agronomy, 2014; 52: 198-209.

[17] Adjorlolo C, Mutanga O, Cho M A. Estimation of canopy nitrogen concentration across $\mathrm{C} 3$ and $\mathrm{C} 4$ grasslands using WorldView-2 multispectral data. IEEE Journal of Selected Topics in Applied Earth Observations and Remote Sensing, 2014; 7(11): 4385-4392.

[18] He T, Jing W, Lin Z J, Ye C. Spectral features of soil organic matter. Geomatics and Information Science of Wuhan University, 2006; 31(11): 975-979.

[19] Phillips J M, Hayman D S. Improved procedures for clearing roots and staining parasitic and vesicular-arbuscular mycorrhizal fungi for rapid assessment of infection. Transactions of the British Mycological Society, 1970; 55: 158 .

[20] Tian Y H, Lei Y B, Zheng Y L, Cai Z Q. Synergistic effect of colonization with arbuscular mycorrhizal fungi improves growth and drought tolerance of Plukenetia volubilis seedlings. Acta Physiol Plant, 2013; 35(3): 687-696.

[21] Li S, Bi Y, Chen P, Liu S, Zhang J, Zhou J, et al. Influence of exogenous calcium on the growth of maize under arid-stress in mine area. Journal of China University of Mining \& Technology, 2013; 42(3): 477-482.

[22] Boochs F, Kupfer G, Dockter K, Kuhbauch W. Shape of the red edge as vitality indicator for plants. International Journal of Remote Sensing, 1990; 11(10): 1741-1753.

[23] Madakadze I C, Stewart K A, Madakadze R M, Peterson P R, Coulman B E, Smith D L. Field evaluation of the chlorophyll meter to predict yield and nitrogen concentration of switchgrass. Journal of Plant Nutrition, 1999; 22(6): 1001-1010.

[24] Arregui L M, Lasa B, Lafarga A, Iraneta I, Baroja E, Quemada M. Evaluation of chlorophyll meters as tools for $\mathrm{N}$ fertilization in winter wheat under humid Mediterranean conditions. European Journal of Agronomy, 2006; 24(2): 140-148.

[25] Demetriadesshah T H, Steven M D, Clark J A. High-resolution derivative spectra in remote-sensing. Remote Sensing of Environment, 1990; 33(1): $55-64$. 